\title{
Phorate (10\%) Poisoning and its Medical Management in a Buffalo
}

\author{
M. Saravanan ${ }^{1 *}$, PK. Ramkumar ${ }^{1}$ K. Kannan ${ }^{1}$, M. Venkatesan ${ }^{2}$, \\ S. Yogeshpriya ${ }^{2}$, P. Selvaraj ${ }^{3}$ and S. Senthilkumar ${ }^{1}$ \\ ${ }^{1}$ Veterinary Clinical Complex, ${ }^{2}$ Department of Veterinary Medicine, Veterinary College and \\ Research Institute, Orathanadu, Thanjavur \\ ${ }^{3}$ Department of Veterinary Clinical Medicine, Madras Veterinary College, Chennai \\ TamilNadu Veterinary and Animal Sciences University, Chennai, India \\ *Corresponding author
}

\section{A B S T R A C T}

\section{Keywords}

Phorate, Buffalo, Atropine sulphate, 2-PAM

\section{Article Info}

Accepted:

28 August 2020

Available Online:

10 September 2020
Phorate is an Organophosphorus insecticide which is widely used in agricultural practice. A 4.5 years old female crossbred buffalo was brought to Large Animal Medicine Referral Clinic, VCC, VCRI, Orathanadu with the history of accidental grazing on pesticide sprayed agriculture field. Buffalo was in lateral recumbency, open mouth breathing with severe respiratory distress, profused salivation, constricted pupils, muscle fasciculation, hyperexcitability, tachycardia, tachypnea and suspended rumination with bloat were observed. The sprayed pesticide sample was found to be Phorate. Treatment was initiated with Inj. Atropine sulphate @ $2 \mathrm{mg} / \mathrm{kg}$ bwt $\left(1 / 4^{\text {th }} \mathrm{IV} \& 3 / 4^{\text {th }} \mathrm{IM}\right)$ followed by Inj. 2-PAM @ $25 \mathrm{mg} / \mathrm{kg}$ bwt IV along with other supportive therapy. Animal started to show clinical improvements after initiation of therapy like cessation of salivation, normal respiration, reduction in muscle fasciculation and normal behaviour, Animal become stabilized after 1 $\mathrm{hr}$ of treatment. The Present case was diagnosed as Phorate poisoning, showed uneventful recovery on early diagnosis and its early therapeutic intervention.

\section{Introduction}

Pesticides are plays a vital role in the agriculture practices to protect plants from pests and other organisms harmful to cultivated plants (Kumar et al., 2013). Developing countries like India, $56.7 \%$ of the peoples were engaged in agriculture activities, hence exposure to pesticides is more common (Gupta, 2004). Pesticides poisoning are frequently encountered problems in animals as a result of accidental grazing at sprayed area (Constable et al., 2017). Phorate is an Organophosphorus compound which is commonly used pesticide to kill insects and pests in the agricultural practice (Bhatt $e t$ al., 2009) and relatively hazardous with $\mathrm{LD}_{50}$ of $1-9 \mathrm{mg} / \mathrm{kg}$ body wt. and cause inhibition of a neurotransmitter acetyl choline esterase (Booth and Mc Donald, 1982), which causes muscarinic effects on respiratory muscles, GI and circulatory system and nicotinic signs in musculoskeletal and delayed neuropathy (Constable et al., 2017). Early diagnosis and 
intervention of appropriate antidote could make better recovery in poisoning. Such that, the present case of accidental ingestion of $10 \%$ Phorate sprayed agriculture field by Murrah buffalo was successfully managed with Atropine sulphate and 2-PAM.

\section{Materials and Methods}

\section{Case presentation and observation}

A 4.5 years old female crossbred buffalo was brought to Large Animal Medicine Referral Clinic of Veterinary Clinical Complex, Veterinary College and Research Institute, Orathanadu with the history of accidental ingestion of pesticide spayed agriculture field 5 hours earlier before the presentation to hopsital. General clinical examination revealed confused and disorientated behaviour, anxious, bloated abdomen, lateral recumbency (Fig. 1), dung and urine not voided. Physical examination revealed congested mucous membrane, hyperthermia $\left(42.2^{\circ} \mathrm{C}\right)$, tachypnea (46/minute) with open mouth breathing, severe respiratory distress, tachycardia (110/minute) and suspended ruminal activity. Profuse salivation, constricted pupils (Fig. 2), muscle fasciculation on shoulder and thoracic region and hyperexcitability were observed.

Asked the owner to bring the sprayed pesticide to identify the type of compound to initiate therapy. Owner had the sample of pesticide that's been sprayed over the field and it was found to be Phorate (in the form of $10 \%$ granules (Fig. 3). Case was confirmed as Phorate poisoning. Treatment was initiated with Inj. Atropine sulphate @ $2 \mathrm{mg} / \mathrm{kg}$ bwt according to the manufacture (Thimet 10G $10 \%$ Phorate granules) dosage as $1 / 4^{\text {th }}$ IV followed by $3 / 4^{\text {th }}$ IM. Inj. 2-PAM @ $25 \mathrm{mg} / \mathrm{kg}$ bwt IV diluted in Normal saline was administered followed by atropinisation. Supportive therapy viz., Inj. Ringers lactate,
Inj. Dexamethasone @ $0.2 \mathrm{mg} / \mathrm{kg}$ IV, Inj. Chlorpheniramine maleate @ $0.5 \mathrm{mg} / \mathrm{kg}$ bwt IM and Powder Activated charcoal @ 450g PO were administered. Animal started to show clinical improvements after initiation of therapy (Fig. 4 and 5). The course and treatment response of the case is given in table 1 .

\section{Results and Discussion}

The present case was diagnosed as Phorate poisoning by the presence of the pesticide bag was brought by the animal owner. Phorate is an organophosphate insecticide that is commonly used as systemic and contact insecticide in agriculture and as acaricide in animals (Gupta, 2004a). Phorate poisoning is one of the commonly reported poisonings in animals (Bhatt et al., 2009) and it was previously reported by and Mahajan et al., (2011) as accidental ingestion in a Murrah buffalo. Phorate inhibits acetylcholine esterase enzyme which causes muscarinic and nicotinic effects (Booth and Mc Donald, 1982) in the non-targeted population like humans and animals. Muscarinic and nicotinic effects due to OPC toxicity could be reversed by administration of atropine sulphate followed by Pralidoxime chloride (2PAM) (Constable et al., 2017). Salivation, hypotension, bradycardia, pupillary constriction, sweating are the common signs due to muscarinic and nicotinic receptor results muscle tremor and tetany, convulsions, opisthotonus, weakness and flaccid paralysis (Constable et al., 2017). In the present case also the signs were recorded except hyperthermia, tachycardia, this may be due to transport of animal by open tempo vehicle which was $2 \mathrm{hrs}$ journey and at that time environmental temperature was high.

The inappropriate use of Organophosphorus substances on agriculture, water and animals may causes direct lethal effect or indirectly by 
the presence of residues in the form of food, fodder, and animal products are ingested/ exposed to the animal and human populations which leads detrimental and lethal effects on exposed population (Fagnani et al., 2011).
Kumar et al., (2013) reported the consequence of direct application of pesticides to the food sources, leads residues effects in food and feed/ fodder and further transfers to the end-users of the food chain.

Table.1 Course of cases and treatment response

\begin{tabular}{|l|}
\hline 9.45 am Case presented to the hospital \\
\hline 10 am Diagnosed as Phorate poisoning \\
\hline @ 10 am Initiation of treatment \\
\hline Response observed \\
\hline @ 10.30 am \\
Cessation of salivation, respiratory distress \\
Respiration becomes normal \\
\hline @ 11 am \\
Normal Pupil \\
Absence of Muscle tremor \\
Absence of hyperexcitability \\
@ 12.30 pm \\
Animal become normal with normal parameters \\
Animal able to stand and voided dung and urine normally \\
Animal was alert and active \\
@ 1.30pm \\
Animal showed uneventful recovery on early diagnosis and \\
itsearly therapeutic intervention \\
Animal was discharged and was advised for review for any \\
relapse occurs
\end{tabular}

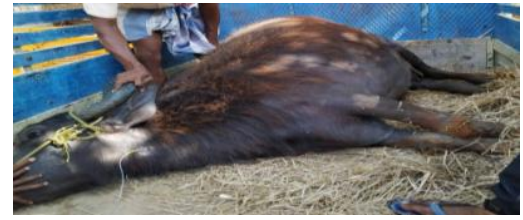

Fig. 1 Animal on lateral recumbency and bloated

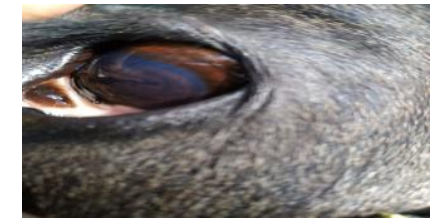

Fig. 2 Constricted Pupil due to Phorate poison

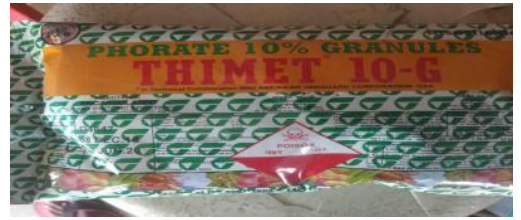

Fig. 3 Sprayed insecticide

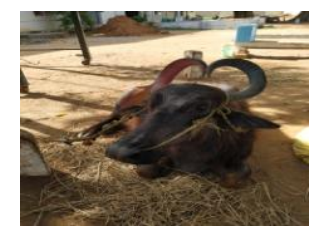

Fig.4 After treatment animal active and on Sternal recumbency

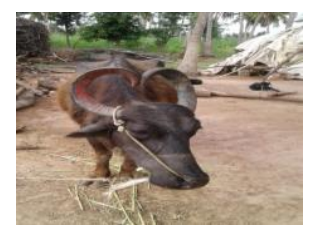

Fig. 5 After treatment animal with normal activity and feed intake 
Davy and Angier (2008); Puschner et al., (2013) reported Contamination of soil and water by Pesticides especially by Phorate is more because phorate compounds phorate sulfoxide and phorate sulfone of their halflives in water of up to 180 days under acidic (pH 5) conditions and are more mobile, and the levels of phorate and its degradation in soil or surface water over time is not clear. Singh et al., (2003) who he has reported that incineration of the Phorate poisoned carcass instead, of burned, Because of these uncertainties related to persistence phorates in soil and/or water and a water table in the area of less than 17 feet ( 5 meters). Puschner et al., (2013) recorded accidental ingestion feed exposed with phorate compound by 167 cows were died acutely and further died cows carcass were disposed by incineration to prevent phorate compounds in the soil.

Acute and accidental poisoning (eg. OPC) can be managed if the poison is identified early, however chronic exposure to such pesticide through agriculture and animal product has possess certain amounts of residuals which leads various diseases and disorders in humans and animals which needs to be studied extensively. Author strongly suggest that the assessment of residual effect of Phorate in a animal, soli and food product to elucidate metabolic derangements in animals as well as human population. Hence, regulatory bodies/agencies should come forward to take necessary action against to control the extensive application of pesticide/insecticides or whatever chemicals were applied to the agriculture and agriculture land.

\section{Acknowledgement}

The Authors are grateful to The Director of Clinics TANUVAS Chennai and Dean VCRI, Orathanadu to provide all the facilities for carrying out this study.

\section{References}

Bhatt, P., D.K. Gupta and V.S. Rajora. 2009. Phorate poisoning in an organized dairy farm. Veterinary Practitioner, 10: 173.

Constable, P.D., K.W. Hinchcliff, S.H. Done and W. Grünberg. 2017. Veterinary Medicine: A Textbook Of The Diseases Of Cattle, Horses, Sheep, Pigs, And Goats, 11th edi. Elsevier, St. Louis, Missouri, pp. 1214-1216.

Davy, M and J. Angier. 2008. Risks of phorate use to federally threatened California red-legged frog (Rana aurora draytonii) to federally threatened Valley elderberry Longhorn beetle (Desmocerus californicus dimorphus) to federally threatened Bay Checkerspot butterfly (Euphydryas editha bayensis) to federally endangered San Joaquin kit fox (Vulpes macrotis mutica). http://citeseerx.ist.psu.edu/viewdoc/dow nload?doi=10.1.1.168.5492\&rep=rep1\&t ype $=$ pdf.

Fagnani, R., Vanerli Beloti, Ana Paula P. Battaglini, Karen da S. Dunga and Ronaldo Tamanini. 2011. Organophosphorus and carbamates residues in milk and feedstuff supplied to dairy cattle. Pesq. Vet. Bras., 31(7):598-602. http://dx.doi.org/10.1590/S0100736X2011000700009.

Gupta, P.K. (2004a). Phorate. Joint Meeting of Pesticide Residues (JMPR), pp 171205.

Gupta, P.K. 2004. Pesticide exposure - Indian scene, Toxicology, 198: 83-90.

Kumar, S., A.K. Sharma, S.S. Rawat, D.K. Jain and S. Ghosh. 2013. Use of pesticides in agriculture and livestock animals and its impact on environment of India. Asian Journal of Environmental Science, 8(1): 51-57.

Mahajan, S., P. Bhatt and Ramakant. 2011. Phorate poisoning in a Buffalo and its 
Therapeutic management. Intas Polivet, 12 (2): 219-220

Puschner., B., Steven Gallego, Elizabeth Tor, Dennis Wilson, Dirk Holstege and Frank Galey. 2013. The Diagnostic Approach and Public Health Implications of Phorate Poisoning In a California Dairy Herd. Clinic Toxicol., S:13.
Singh, N., B. Singh, P. Dureja and N. Sethunathan. 2003. Persistence of phorate in soils: role of moisture, temperature, pre exposure, and microorganisms. J Environ Sci Health., B 38: 723-735.

\section{How to cite this article:}

Saravanan, M., P. K. Ramkumar, K. Kannan, M. Venkatesan, S. Yogeshpriya, P. Selvaraj and Senthilkumar, S. 2020. Phorate (10\%) Poisoning and its Medical Management in a Buffalo Int.J.Curr.Microbiol.App.Sci. 9(09): 3679-3683. doi: https://doi.org/10.20546/ijcmas.2020.909.454 